\author{
G. V. TITENKO ${ }^{1}$, PhD, Assoc Prof., K. B. UTKINA ${ }^{1}$, PhD, Assoc Prof., \\ N. V. MAKSYMENKO ${ }^{1}$, Doctor of Sciences, Prof., A. N. NEKOS ${ }^{1}$, Doctor of Sciences, Prof., \\ Anton SHKARUBA ${ }^{2}, \mathrm{PhD}$ \\ ${ }^{l}$ V. N. Karazin Kharkiv National University, Ukraine. \\ ${ }^{2}$ Estonian University of Life Sciences, Estonia
}

\title{
ERASMUS+ PROJECT «INTEGRATED DOCTORAL PROGRAM FOR ENVIRONMENTAL POLICY, MANAGEMENT AND TECHNOLOGY - INTENSE»: PROGRESS INFORMATION AND PLANNED ACTIVITY
}

Erasmus + project "Integrated Doctoral Program for Environmental Policy, Management and Technology - INTENSE” (586471-EPP-1-2017-1-EE-EPPKA2-CBHE-JP) stated in 2017. The project addresses such root causes of environmental problems in Mongolia, Ukraine and Vietnam, as poorly formulated policies, inadequate selection of management actions and the lack of suitable technology, by building capacity for academic excellence in doctoral training in environmental studies in partner countries (PCs) and beyond. Consortium consists of universities and research institutions from Ukraine, Estonia, Austria, Latvia, Mongolia and Vietnam.

One of the key planned outcomes of Erasmus+ project "Integrated Doctoral Program for Environmental Policy, Management and Technology - INTENSE" is development of Massive Open Online Courses (MOOCs). MOOC is an online course aimed at unlimited participation and open access via the web. In addition to traditional course materials, such as filmed lectures, readings, and problem sets, many MOOCs provide interactive courses with user forums to support community interactions among students, professors, and teaching assistants, as well as immediate feedback to quick quizzes and assignments

In the framework of INTENSE project it is planned to develop several MOOCs, one will be "The precautionary principle and sustainability transition". The leader is V. N. Karazin Kharkiv National University and all partners will make their contributions. Currently the contents of the MOOC are under discussion; there were several structures already discussed and the updated one will include the following modules and topics.

Module 1 - Development trends in context of sustainability

Module 2 - Sustainability challenges and lessons to learn

Module 3 - Sustainable Consumption and Production

Module 4 - Social Justice

Another key output will be developed courses. KKNU team is developing the following courses for PhD students:

- Philosophy of Science

- Science Methodology

- Practice Learning in University Teaching

- Mathematical Statistics and Modelling

- Environmental Policy and Management

- Sustainable Development

- Natural Resource Science

In addition to these courses there will be three elective courses. schools:

During the INTENSE project implementation $\mathrm{PhD}$ students have participated in three summer

- The precautionary principle in sustainability transitions: thinking forwards, looking backwards, acting, Budapest (2018)

- Nature-based solutions for smart cities, Mohilev (2018) (Foto 1).

- Win! Water innovations: policy, management, research, Tartu (2019) (Foto2).

KKNU staff members have participated in workshop "ICT tools and methods for curriculum development", Tartu (2019) (Foto 3). 


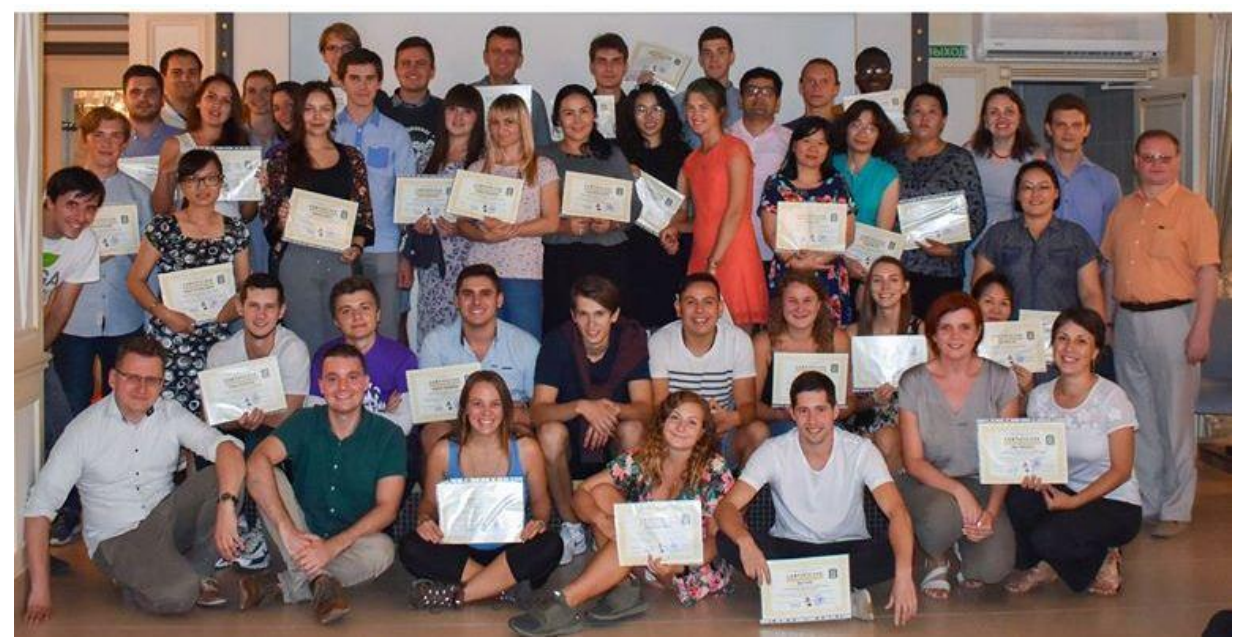

Foto 1 - PhD students Dudchenko V. and S. Shirokostup at the summer school in Mohilev

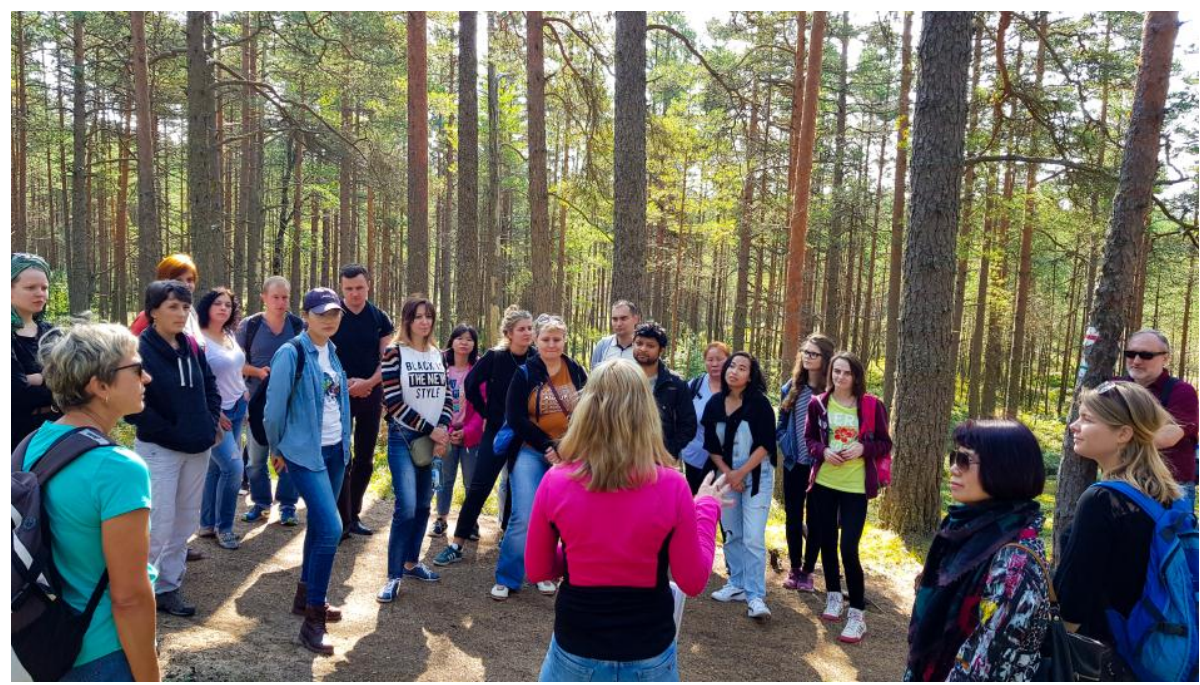

Foto 2 - PhD student Burchenko S. at summer school in Tartu

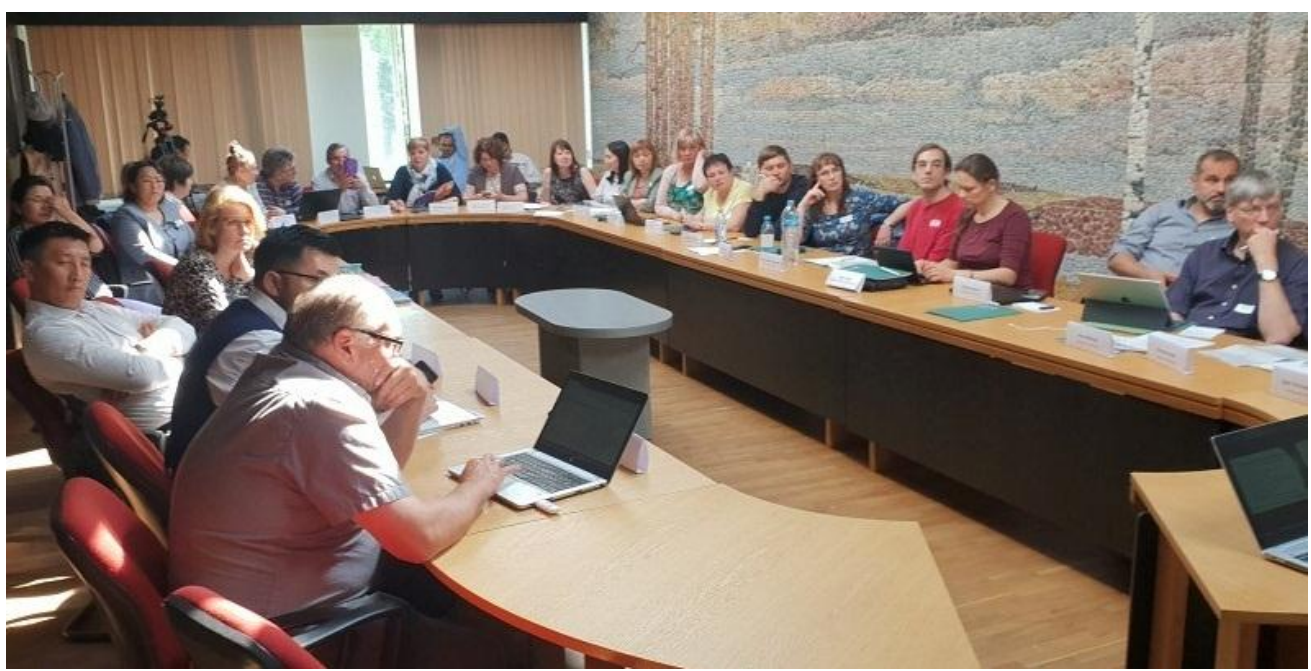

Foto 3 - Professors Maksymenko N. V., Nekos A. N. and Chernikova O. Yu. on the workshop "ICT tools and methods for curriculum development" 


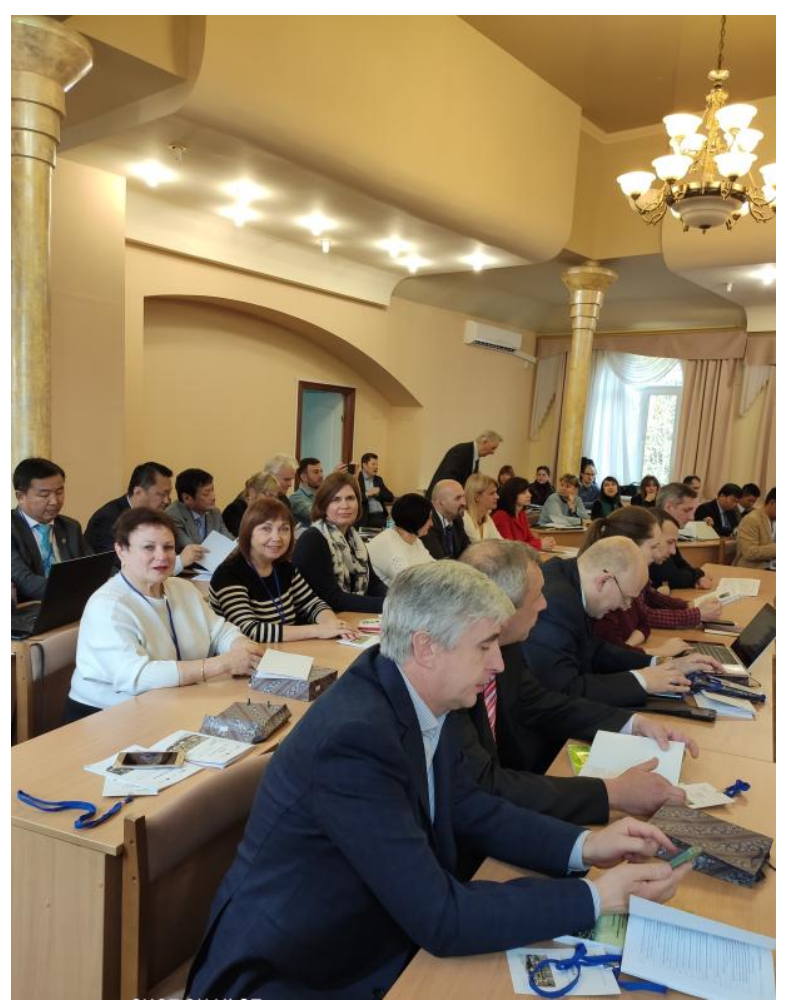

Foto 4 - Professors Nekos A. N., Maksymenko N. V., Utkina K. B. on Conference 'Smart Green \& Smart Blue"
Also in November 2019 KKNU staff members took part in Open Science Conference 'Smart Green \& Smart Blue: exploring naturebased solutions and ecosystem services approaches in environmental management, planning \& policy', Lviv (Foto 4). A conference took stock of smart green and smart blue solutions for urban and territorial sustainability, with a particular focus on transfer and applicability of policy, management and technology innovation. It addressed the following areas:

- Urban regeneration through nature-based solutions

- Nature-based solutions for improving wellbeing in urban areas

- Green and blue infrastructure in physical planning and landscape architecture

- Multi-functional nature-based watershed management and ecosystem restoration

- Nature-based solutions for increasing the sustainability of the use of matter and energy

- Nature-based solutions for enhancing the insurance value of ecosystems

- Increasing carbon sequestration through nature-based solutions

- Green (including biobased, circular etc) economy for cities and territorial resilience

- Integration of cultural values and ecosystem services in planning and environmental management

Among key speakers there were EU and UA specialists. KKNU team members made several reports concerning the use landscape segment of ecosystem services in management decision, information on MOOC "The precautionary principle and sustainability transition" structure and methods and techniques for practice learning.

On the Conference the Framework agreement on the establishment of the international doctoral school network INTENSE was signed by all participants. It will be the basis to promote joint educational and research collaboration and promote objectives of joint doctoral training in future.

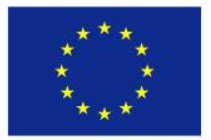

Co-funded by the Erasmus+ Programme of the European Union
The publication was prepared in the framework of ERASMUS+ project "Integrated Doctoral Program for Environmental Policy, Management and Technology INTENSE", financed by European Commission. Responsibility for the information and views set out in this publication lies entirely with the authors. 